\title{
O ESTÁGIO SUPERVISIONADO COMO POSSIBILIDADE DE VALORIZAÇÃO DO ENSINO DE LÍNGUAS E CULTURAS INDÍGENAS POR MEIO DE ABORDAGENS DIGITAIS
}

\begin{abstract}
Adriana Oliveira de Sales*
RESUMO: As populações indígenas brasileiras têm o direito a uma Educação Escolar Diferenciada. A partir desse reconhecimento pelas instituições governamentais e sociais, foram criados cursos de Licenciaturas Interculturais Indígenas. Nesses cursos, desenvolvemos um trabalho no âmbito das formações diferenciadas e específicas para indígenas Guarani e Kaiowá de Mato Grosso do Sul, sobretudo, na Universidade Federal da Grande Dourados que criou o Curso de Licenciatura Intercultural Indígena Teko Arandu em 2006 e tem respondido com uma demanda crescente a formação de professores indígenas. Nesse sentido, aliamos a disciplina de Estágio Supervisionado em Linguagens I e II para desenvolver atividades a partir da compreensão de um bilinguismo intercultural situado na observação do ensino da primeira língua (L1) e da segunda língua (L2). Os questionamentos gerados sugerem a seguinte situação: no que se refere ao desenvolvimento de um sujeito bilíngue - em que seja possível manter a língua materna e segunda língua desenvolvendo todas as habilidades comunicativas (falar, entender, ler e escrever), ainda que essas sejam desenvolvidas em níveis diferentes em ambas as línguas. Bem como, situar os estudantes na condição escolar indígena e de que maneira as novas tecnologias e o acesso à universidade podem fortalecer as línguas indígenas que correm risco de extinção, e ainda, as culturas que podem ser diluídas no processo de colonização. Reconhecemos que as diferentes experiências de que temos participado nos possibilitam constantes questionamentos com relação à educação escolar e à escola em sociedades culturalmente diferentes.
\end{abstract}

ABSTRACT: Brazilian indigenous populations have the right to Differentiated School Education. From this recognition by governmental and social institutions, courses on Indigenous Intercultural Undergraduate Courses were created. In these courses, we developed a work in the scope of differentiated and specific training for Guarani and Kaiowá indigenous people from Mato Grosso do Sul, especially at the Federal University of Grande Dourados, which created the Teko Arandu Indigenous Intercultural Degree Course in 2006 and has responded with a demand the training of indigenous teachers is increasing. In this sense, we combine the discipline of Supervised Internship in Languages I and II to develop activities from the understanding of an intercultural bilingualism situated in the observation of the teaching of the first language (L1) and the second language (L2). The questions generated suggest the following situation: with regard to the development of a bilingual subject - in which it is possible to maintain the mother tongue and second language by developing all communicative skills (speaking, understanding, reading and writing), even if these are developed at different levels in both languages. As well as, placing students in the indigenous school condition and how new technologies and access to university can strengthen indigenous languages that are at risk of extinction, as well as cultures that can be diluted in the colonization process. We recognize that the different experiences that we have participated in enable us to constantly question school education and schooling in culturally different societies.

PALAVRAS - CHAVE: Licenciatura Indígena; Ensino de Línguas; Abordagens Digitais.

KEY WORDS: Indigenous degree; Language teaching; Digital Approaches 

NECESSIDADE DE PRESERVAÇÃO DAS LÍNGUAS E CULTURAS INDÍGENAS

Mato Grosso do Sul possui a segunda maior população indígena do Brasil, ficando atrás apenas do estado do Amazonas. No ano de 2010, alcançava 73.295 indivíduos (Censo, 2010). Compondo doze etnias, sendo: Guarani, Kaiowá, Ofaié, Guató, Bororo, Terena, Kinikinau, Chamacoco, Camba, Kadiwéu, Atikum e Ayoreo.

Dessas etnias que vivem no Estado, cabe destacar que a maior parte da população pertencente às etnias Kaiowá e Guarani, esses, ainda falam suas línguas maternas, mas segundo a UNESCO (2010), são línguas que correm risco de extinção por serem consideradas como vulneráveis (com falantes de Kaiowá em um número de 20.000 indivíduos e Guarani Nandeva com um número de 10.000 indivíduos), isto é, a maioria das crianças fala a língua, porém seu uso pode estar restrito a determinados contextos (familiar, rituais religiosos, etc.). Com relação a essas línguas, ainda é preciso observar outro importante aspecto, que é o contexto de outras línguas e a interferência sobre as línguas indígenas.

\footnotetext{
Ainda sobre as línguas Kaiowá e Guarani, cabe lembrar que ambas estão sob a influência sistemática do Guarani paraguaio, do espanhol e, sobretudo, do português. E conhecendo o Kaiowa e o Guarani falados pela população indígena mais velha e registrado por escrito, é possível observar que a distinção linguística vem diminuindo rapidamente entre essas línguas, em direção a um Guarani standard, uma espécie de "língua franca" socializada entre as novas gerações (MARTINS \& CHAMORRO, 2015).
}

No caso específico das comunidades indígenas de Mato Grosso do Sul, algumas atitudes vêm sendo tomadas para criar condições propícias para que os falantes sigam usando sua língua materna e a ensinem às suas crianças e, por conseguinte, às novas gerações. Cabe destacar, então, a criação de cursos específicos de formação de professores indígenas em nível superior.

O curso de Licenciatura Intercultural Indígena foi criado na Universidade Federal da Grande Dourados em 2006, posteriormente, por meio da publicação da Portaria ${ }^{\circ} 435$ de 21 de maio de 2012, publicado no Diário Oficial da União em 29/05/2012 criou-se a Faculdade Intercultural Indígena (FAIND). Oferece, habilitações em quatro áreas de conhecimento: Ciências Humanas, ou Linguagens, ou Matemática ou em Ciências da Natureza. Assim, os alunos têm sua certificação e diplomação, de acordo com a habilitação escolhida. O Curso é presencial e oferecido através da metodologia da Alternância. Alternância é entendida como uma formação que ocorre durante tempos distintos vividos pelo acadêmico e corpo docente: Tempo Universidade e Tempo Comunidade. 
Durante a alternância de tempos, a formação acorre, a partir de uma intervenção pedagógica e social capaz de refletir na prática da comunidade que o educando faz parte. O Curso é composto por dois Blocos: Bloco I também denominado Núcleo Comum (de um ano e meio) com um currículo único para todos os acadêmicos e Bloco II também denominado Núcleo Específico (de três anos).

O currículo está embasado nos aspectos centrais da construção de uma educação escolar indígena diferenciada, específica, bilíngue, autônoma e intercultural. Implica em criar condições favoráveis para desenvolver o processo de descoberta, pesquisa, criação e apropriação de conhecimentos, aborda o ser humano em todas as suas dimensões de vida - social, política, cultural, familiar, religiosa, biológica, econômica, visa através da compreensão do outro, diminuir as assimetrias e buscar outras formas de modernidade ao articular conhecimentos e valores socioculturais distintos, de forma seletiva, crítica e reflexiva, sem hierarquia de saberes.

Para suprir em parte a necessidade intercultural, é assegurada também, durante o curso, a participação efetiva de caciques/“rezadores" Guarani e Kaiowá (mestres tradicionais/ñanderu) os quais garantem a orientação de questões próprias da cultura tradicional, sob seu ponto de vista.

Tem ainda, a proposta do curso embasada em uma opção política de valorização da língua materna, colocando no mesmo patamar de prestígio da língua nacional, em todas as suas modalidades, garantindo a efetivação da comunicação e da produção de conhecimentos. A licenciatura está constituída em três grandes eixos: teko (cultura), tekoha (território) e $\tilde{n} e^{\prime} \ddot{e}$ (língua), que são os aspectos fundamentais pelos quais se articularam os conteúdos e a metodologia do curso: (a) Tekoha 'Território': "é o lugar em que vivemos segundo nossos costumes".

Assim, as atividades curriculares teóricas e práticas de um trabalho como esse, têm como princípios metodológicos a interculturalidade e a transversalidade dos eixos propostos, os conhecimentos e competências antropológicas e pedagógicas, que possibilitam novas atitudes epistemológicas frente aos conteúdos trabalhados. Respeitando o modo de ser e viver, faz-se a relação teoria-prática.

Outra questão que deve ser explicada, é: Como o indígena acessa esse curso? Como ele consegue ser estudante da licenciatura indígena? Pensando nisso, há também uma entrada diferenciada. A realização do Processo Seletivo Vestibular da Licenciatura Intercultural Indígena - PSLIN, composto por três fases:

1. Prova de Redação em Língua Guarani (considerando suas variações) e em língua Portuguesa (considerando-a como uma segunda língua); 
2. Prova Oral em Língua Guarani (considerando suas variações);

3. Prova Objetiva de conhecimentos gerais sobre Ciências Humanas, Legislação Indigenista, Matemática, Ciências da Natureza e questões referentes à realidade indígena.

Nenhuma das fases elimina o candidato, todas são classificatórias, essa seleção ocorre a cada um ano e meio e está entre as mais concorridas das licenciaturas na UFGD.

As atividades relatadas, foram desenvolvidas na área de linguagens. A proposta dessa área é oferecer uma formação intercultural, bilíngue e multidisciplinar. Habilita professores indígenas bilíngues Guarani/Kaiowá para atuarem no Ensino Fundamental ( $6^{\circ}$ ao $9^{\circ}$ ano) e no Ensino Médio nas seguintes áreas de conhecimento: Língua Guarani; Língua Portuguesa como Segunda Língua; Artes e Educação Física. Possui 9 semestres e 33 disciplinas, contabilizando 2.740 horas de Bloco Específico.

A disciplina de Estágio inicia no oitavo semestre da área específica e abarca como ementa, o estudo das leis que regem os estágios e noções de produção de relatórios. Pensar a prática pedagógica dos acadêmicos da área de Linguagens, visando uma atuação em Língua Portuguesa, Língua Guarani, Artes e Educação Física no Ensino Fundamental e Médio das escolas indígenas Guarani/Kaiowá, além de buscar a articulação entre a aprendizagem durante as etapas de estudos intensivos (Tempo Universidade - TU) e a prática de organização e execução do trabalho pedagógico nas escolas indígenas (Tempo Comunidade - TC).

Dessa forma, ensejou-se aproximar as atividades pedagógicas desenvolvidas no Estágio Supervisionado em Linguagens com as atividades de produção de vídeo aulas para o ensino de Língua Indígena nas escolas e um Curso Preparatório para o Vestibular da Licenciatura Intercultural Indígena com o intuito de valorizar e fortalecer as línguas das escolas indígenas e as culturas dos estudantes.

\section{OBJETIVOS DO ESTÁGIO NA ÁREA DE LINGUAGENS}

As atividades tiveram pressupostos de aprendizagem social, profissional, cultural e de ação pedagógica que envolve estudo, pesquisa, análise, problematização, reflexão e proposição de soluções às situações de ensino e aprendizagem nas escolas indígenas no Ensino Fundamental e, no Ensino Médio. Dessa forma, os objetivos propostos foram:

a) Refletir sobre a prática docente, desenvolvendo uma postura crítica sobre a educação indígena e escolar indígena, estabelecendo uma articulação teórica e prática no atual contexto da territorialidade indígena e no contexto sócio-político-econômico geral; 
b) Analisar a oferta de ensino nas escolas indígenas com relação ao ensino fundamental e médio das aldeias indígenas.

c) Propiciar a vivência no exercício efetivo da prática de professor nas escolas indígenas ou não indígenas, na sala de aula.

d) Refletir sobre a prática pedagógica nas escolas, considerando a interdisciplinaridade;

e) Propiciar aos discentes condições para que estes possam experimentar situações de ensinar, aprender a elaborar, executar e avaliar projetos de ensino nas salas de aula, bem como na comunidade, e aprender a elaborar, executar e avaliar projetos pedagógicos das escolas indígenas.

f) Desenvolver competências linguísticas nas línguas Guarani/Kaiowá no âmbito da oralidade e da escrita.

g) Desenvolver competências linguísticas com relação a produção de textos em Português como Segunda Língua

h) Desenvolver metodologias de ensino de línguas por meio da utilização de tecnologias que estão disponíveis nas aldeias indígenas.

i) Fortalecer o Vestibular da Licenciatura Intercultural Indígena -Teko Arandu

\section{CONTEÚDOS CURRICULARES PRIORIZADOS: SOBRE O ENSINO E A FORMAÇÃO DE PROFESSORES INDÍGENAS}

Em termos de conteúdos curriculares priorizados nesse trabalho, adotamos prioritariamente a proposta de reconhecimento da educação escolar indígena e a oferta de uma formação intercultural, bilíngue e multidisciplinar.

Dessa forma, resguardamos tempo de observação e entendimento de como funciona a Educação Escolar Indígena e como se dá o ensino nessas comunidades. De maneira, que conseguimos pensar e organizar melhor os conteúdos a serem trabalhados para a preparação de professores no que se refere ao ensino, principalmente das línguas. No que diz respeito à formação bilíngue proposta no curso, compreendemos que a língua indígena deve ser tratada como L1 (Língua 1) e a língua portuguesa como L2 (Língua 2). Buscouse ainda, o caráter multidisciplinar por meio de atividades curriculares que contemplem o desenvolvimento de conhecimentos sobre Línguas, Artes e Educação Física.

Foram ministrados conteúdos que possibilitam ao professor de línguas embasamentos para trabalhar metodologia do ensino de língua materna no que tange à descrição da estrutura e do funcionamento dela. Outros conteúdos são para dar maior visibilidade e funcionalidade da língua indígena, além das concepções de língua e linguagem, os conceitos básicos de ensino de línguas, análise de métodos de ensino de língua com primeira e como segunda língua. Na perspectiva da oralidade e da escrita no ensino de 
línguas, foram apontadas as condições de produção do texto oral e escrito de diversos gêneros textuais e discursivos.

Assume-se, portanto, a responsabilidade de formar professores que tenham uma visão mais central no ensino para comunidade guarani e kaiowá, tendo em vista que as sociedades indígenas no Brasil não faziam uso de nenhuma forma de escrita stricto sensu, anteriormente à chegada dos europeus. Depois do contato com a sociedade não indígena e com a escrita do Português, em muitas comunidades surgiram pessoas alfabetizadas que passaram a fazer uso da escrita para comunicação em língua portuguesa. Não havia motivos para uso da escrita em língua indígena e eles não tentaram fazê-la.

Entretanto, o passar do tempo trouxe outros sintomas da presença cada vez mais intensa dos não-índios no entorno das aldeias e, mesmo, na vida das comunidades indígenas, particularmente no século XX: a entrada da escola (ou ensino escolar) nas aldeias. No bojo desse novo contexto, professores e lideranças indígenas passaram a refletir e a buscar, coletivamente, formas de tornar o ensino escolar efetivamente útil para o interesse das comunidades, sobretudo buscando fortalecer suas culturas e línguas.

Ao longo do tempo, o bilinguismo tornou-se uma necessidade para as comunidades indígenas à medida em que os contatos e relações com a sociedade dominante foram se intensificando.

Como o "falar português", também "ler e escrever" português torna-se, em algum momento, uma necessidade coletiva de uma comunidade indígena em contato permanente com a sociedade brasileira. Pressionadas por documentos oficiais ou não, ou obrigadas a conviver com o registro escrito de contas e haveres, as comunidades passam a sentir a necessidade de dominar esse instrumento pelo qual, percebem, começam a ser manipulas ou prejudicadas.

Do mesmo modo que o domínio oral do Português, a necessidade do domínio da escrita (ao menos, da leitura, em português) aos poucos se torna, em muitas comunidades, uma necessidade familiar por conta das condições de trabalho.

Nesse sentido, escola e escrita, começam em meados do século XIX, segundo D'angelis (2007) todo um processo de "integração do índio" por meio da escola e da escrita da língua nacional. A escola que é levada para as comunidades indígenas é uma escola monolíngue em português e o objetivo dessa escola era o de "integrar" o índio a sociedade e a língua nacional e combater as crenças, valores e práticas indígenas. Esse sistema criado pelo Serviço de Proteção aos índios e reforçado pelo Summer Institute of Linguistcs, dessa forma, a escola cria uma geração de jovens alfabetizados e que passam a abrir espaços a novas demandas, nas aldeias, entre elas as de emprego, uma das principais demandas hoje com relação a escolarização, é a formação indígena em cursos 
superiores. Não se tem dados precisos quanto ao ingresso dos indígenas nas universidades brasileiras, na UFGD tem-se 210 indígenas matriculados na Licenciatura Intercultural e cerca de 150 em outros cursos da universidade, o que se percebe, de maneira geral é uma demanda em estado crescente.

Com os empregos advindos ou relacionados à escolarização para os membros de uma elite indígena nas comunidades, ao longo dos anos foram criando "modelos" de carreira pessoal. Seja na forma de uma aspiração de emprego, seja por uma aspiração genérica pela qual os pais mandam seus filhos à escola para "serem alguém na vida" o fato é que muitas comunidades indígenas vão, nesse processo, rendendo-se a busca de saídas individuais para as situações que vivenciam. A valorização da leitura e da escrita são, então, parte de um processo de valorização da escola como um todo.

Isso não seria problema, se no processo de escolarização e ensino de línguas nas aldeias a língua portuguesa passasse a dominar todo o sistema de ensino. Causando a apagamento e até a extinção de muitas línguas indígenas. Não seria problema se as escolas Guarani/Kaiowá de Mato Grosso do Sul não tivesse se tornado um espaço de desvalorização da língua indígena, por conta dessa urgência no ensino da língua portuguesa.

Elas possuem a tipologia de Educação Escolar Indígena, bilíngue e diferenciada, mas, em suas grades curriculares, a língua materna ocupa um espaço de ponte para língua portuguesa. Com diferentes realidades, mas com um ponto em comum: a falta de uma educação linguística que viabilize o ensino da língua indígena efetivamente e o ensino da língua portuguesa com fins específicos.

A educação intercultural bilíngue, em muitos casos, é uma farsa (D’angelis, 2012), já que não é interculturalidade quando o indígena é destinado a aprender e integrar-se na cultura da sociedade nacional em detrimento da cultura local.

Com relação ao ensino de línguas, muitos professores não - índios enviados às aldeias para ensinar o português não estão preparados para o contato com um falante de outra língua materna e com outra cultura, muito diferente da sua. Dessa forma, ensinam o idioma como se fosse a primeira língua, com materiais e programas voltados ao ensino de gramática normativa que possuem abordagens e métodos de ensino de língua materna, além desses professores desconhecerem metodologias de ensino de L2.

Além disso, muitos professores não sabem que as culturas indígenas são culturas orais, ou seja, não têm tradição escrita, o que dificulta e muito o aprendizado da modalidade escrita do português padrão. Quando o professor é indígena e ensina a língua portuguesa, também há problemas na formação. Ele repete as práticas de primeira língua, além de desconhecer as metodologias de ensino. 
Não há materiais e recursos didáticos para esse fim específico, os materiais utilizados nas escolas indígenas, são livros didáticos de língua portuguesa como primeira língua, situação essa que não corrobora para o ensino de PSL. Outras situações relevantes no processo ensino-aprendizagem, foram levantadas por Barbosa e Sales (2017).

Elas, apontam que na sala de aula de português na Escola Indígena da Aldeia Teylikue, Caarapó, MS, por exemplo, os conteúdos trabalhados são em sua maioria textos sem explicação: utilizam textos extensos para estudantes Guarani e Kaiowá, e não explicam, isso mostra o despreparo do professor, para desenvolver as competências da oralidade (falar), leitura (ler e ouvir), Escrita (escrever e reescrever), e a análise linguística. Na sala de aula o professor não explica situações básicas como vocabulário, pois subtende-se que não é importante os significados, fato que mostra mais uma vez, que ele não está preparado para ensinar segunda língua;

Outro aspecto apresentado por Barbosa e Sales (2017), é a ligação de diagnósticos dados erroneamente para alunos indígenas. Encaminham alunos para a educação especial, como se eles fossem deficientes intelectuais, quando na verdade o que se apresenta fortemente é a falta de preparo do professor no que se refere ao ensino de línguas. O problema não é saúde, o problema é linguístico e a ignorância desse processo faz com que alunos sejam taxados como deficientes; aspectos culturais também influenciam no processo de ensinoaprendizagem do aluno indígena nas aulas de língua portuguesa. Na cultura Guarani e Kaiowá as mães criam seus filhos com tom de voz suave, quando chama atenção é um diálogo normal sem alterar a voz, principalmente quando é família kaiowá.

A realidade da proficiência e uso das línguas, variam muito de aldeia para aldeia. Todavia, apresento de maneira geral a realidade sociolinguística das aldeias indígenas no cone sul de Mato Grosso do Sul, baseado nas observações dos alunos:

A maioria dos homens e mulheres falam português, com nível de fluência que variam do razoável ao bom, sendo bem compreendidos pela população do entorno, com quem têm contato frequente devido à proximidade das aldeias com as cidades. As crianças, até atingirem a idade escolar, tem pouco contato com a língua portuguesa, entre cinco e seis anos, falam a língua materna. Em sua maioria, quando entram para a escola, sediada nas próprias aldeias, é que aprendem o português falado e escrito.

Os adultos vão com frequência à cidade, comprar mantimentos, fazer tratamento de saúde e, no caso dos mais velhos, receber aposentadoria, há nesses últimos anos uma entronização frequente de meios de comunicação e o uso da internet, principalmente via celular. Nesse sentido, compreendemos que é papel e função da escola o desenvolvimento e aprimoramento das competências comunicativas (falar e entender, ler e escrever). Embora, reconheçamos, que não necessariamente seja somente a partir da escola que as crianças tenham acesso à língua portuguesa. 
Todos os conteúdos curriculares citados têm essa perspectiva. Por meio deles, aborda-se a capacitação em língua materna a partir de reflexões linguísticas, envolvendo conhecimentos de fonética, fonologia, morfologia e sintaxe; e de linguística aplicada, numa reflexão sobre a língua, que permita ao professor em formação interpretar as produções linguísticas de seus alunos (orais ou escritas). Vislumbra-se que esses consigam lidar com a variação dialetal, mudanças linguísticas e com as atividades dos alunos enquanto falantes e capazes de pensar a sua própria organização comunicacional.

Por essas e outras razões, o momento de se pensar a prática pedagógica, o momento do estágio supervisionado é tão importante na formação dos professores indígenas e podem adotar práticas de valorização ou não das suas línguas e culturas.

As formações oferecidas para a realização das provas do vestibular também possuem esse viés. Os conteúdos trabalhados sobre a redação em língua portuguesa levaram em conta que ela é considerada como segunda língua da comunidade com a qual trabalhamos. As aulas, nesse sentido abordou estudos linguísticos de ensino de português como L2 tais como: ensino de português para trabalhadores imigrantes principalmente em contexto urbano (Amado 2011; Vieira 2011); Português e as línguas nas fronteiras - ensino de português para falantes de outras línguas em contexto de fronteira com o Brasil (Pereira 2011); Bilinguismo de escola - ensino de português para alunos estrangeiros nas escolas bilíngues (e monolíngues) brasileiras ( Neves 2011; Andrade 2011), Ferreira Netto (1994a, 1994b, 1997a, 1997b) sobre a educação indígena e o português entre os guarani, os wajãpi, os terena e os timbira, os estudos organizados por Mattos e Silva (1988), de Lima Hernandes e Ferreira Netto (2002) sobre o português entre os kamayurá, os estudos organizados por Roncarati e Mollica (1997) sobre o português falado por povos do Xingu, o estudo realizado por Ferreira (2005) sobre o português entre os parkatejê, o estudo realizado por Abram dos Santos (2006), sobre o português escrito entre os wajãpi, e o estudo de Amado (2009, 2010, 2011.).

Outro conteúdo trabalhado diz respeito a realização de uma prova de redação escrita em língua Guarani ou Kaiowá. Esse é um aspecto relevante adotado, que apresenta, como temos colocado, a língua materna de nossos alunos em um local de excelência. Essa é uma maneira de ampliar o uso da modalidade escrita para além da escola. Importante ressaltar que a prova na língua materna tem motivado adolescentes do ensino médio a estudarem cada vez mais sua própria língua. Essa é também uma forma de dar prestígio para a língua, fato que temos percebido como positivo, pois as escolas de Ensino Médio que se localizam em áreas indígenas passaram a rever a forma como adotam as línguas Guarani e Kaiowá em seu currículo, por conta, justamente, de como elas vêm sendo prestigiadas no processo seletivo do Teko Arandu. Ao avaliar a habilidade escrita da língua indígena, pretendemos ajudar a tornar funcional essa nova modalidade da língua. 
Outro aspecto importante foi estudar a oralidade. Ela constitui o ponto mais positivo daquilo que temos definido como política linguística de valorização da língua materna e um dos principais motes dos estudantes estagiários. De alguma forma, essa atividade valoriza a modalidade mais funcional da língua dentro das comunidades indígenas.

Nesse sentido, o espaço que se pensa dentro do estágio supervisionado é que por meio de uma educação linguística, se dê a construção de conhecimentos linguísticos e que este processo garanta, de alguma forma, o surgimento de outros conhecimentos sobre a língua indígena muito superior àqueles já desenvolvidos por linguistas com dados colhidos em campos de pesquisa. Sem desmerecer, é claro, estes trabalhos, mas a ideia é conseguir interpor esses conhecimentos para a formação de um professor indígena autônomo, pensante da sua própria língua e do seu trabalho com ela.

Por fim, cabe ressaltar que estamos cientes de que o Teko Arandu não dá e não dará conta de resolver os problemas da Educação Escolar Indígena dos Guarani e dos Kaiowá, tampouco duas disciplinas estágio, todavia não acentuará os problemas já existentes, pelo contrário, estamos sempre pensando de que forma é possível sonhar com uma escola inteiramente indígena e acreditamos, para tanto, que a língua indígena deva ocupar um espaço privilegiado na formação dos alunos indígenas, em qualquer nível de ensino; no entanto, nessa luta, é preciso rever por completo o sistema de educação bilíngue que está posto.

\section{PROCEDIMENTOS DIDÁTICOS E EXPERIÊNCIAS DIGITAIS:}

As atividades foram desenvolvidas com duas turmas de Estágio Supervisionado, que contavam com 35 estudantes de diferentes municípios e aldeias (Japorã - aldeia Porto Lindo; Amambai - Aldeias Guapoi e Limão Verde; Dourados - Aldeias Jaguapiru, Bororo e Panambizinho; Tacuru - Aldeia Jaguapire e Sassoró; Antônio João - Campestre; Paranhos - Aldeias Pirajuí, Potrero Guaçu; Caarapó - aldeia Tey'ikue;Bela Vista - aldeia Pirakua; Coronel Sapucaia - aldeia Taquapery; Laguna Carapã - aldeia Guaimbé).

Inicialmente apresentamos as possibilidades do Estágio, e como esses estudantes poderiam desenvolver as atividades no decorrer dos semestres. Como professora responsável, expliquei quais as possibilidades de trabalharmos com a produção de vídeo aulas em Guarani e vídeo aulas em Português nas aulas acorridas no ano de 2016 e como poderíamos aliar as atividades de estágio também ao processo seletivo vestibular ocorrido no primeiro semestre de 2017. 
O mote para todas essas atividades foi a realidade educacional do campo de estágio a partir do desenvolvimento de atividades relativas à docência e às observações escolares de forma a estabelecer a interação entre os professores, alunos, comunidade indígena e os conteúdos educativos, nos quais se mobilizaram, valorizando e articulando os diferentes saberes pedagógicos (escolares e não escolares), procedendo a uma análise crítica fundamentada teoricamente e legitimada no contexto das comunidades indígenas.

Como componente obrigatório do curso, possui carga horária total de 400h, abrangendo o Ensino Fundamental e o Ensino Médio, conforme Projeto Pedagógico do Curso, divididos em: Estágio Supervisionado I, de Julho a dezembro de 2016 - 200 horas Estágio Supervisionado II, de janeiro a junho de 2017- 200 horas. Essa carga horária foi dividida no Tempo Universidade 60 horas e Tempo Comunidade 140 horas em cada disciplina.

As atuações dos estudantes compreenderam:

I - Monitorias;

II - Projetos de ensino e de intervenção pedagógica;

III - Minicurso;

IV - Oficinas;

V - Projetos voltados à comunidade em espaços não escolares, que envolvam práticas pedagógicas;

As atividades foram organizadas da seguinte forma:

\begin{tabular}{|l|l|}
\hline Etapa presencial - Tempo Universidade & 30 horas \\
\hline Etapa presencial - Tempo Universidade & 30 horas \\
\hline Observação de aulas - Tempo Comunidade & 40 horas - sendo: \\
& 10 horas em Português como segunda \\
& língua \\
& 10 horas em Língua Guarani \\
& 10 horas em Educação Física \\
\hline Aulas, minicursos, oficinas e projetos - Tempo & 10 horas em artes \\
Comunidade & 60 horas - sendo: \\
& 15 horas em Português como segunda \\
& língua \\
\hline Escrita, organização e revisão de relatórios & 15 horas em Língua Guarani \\
\hline
\end{tabular}

A divisão em tempo universidade e tempo comunidade é importante pois no período em que os alunos estiveram na universidade foram feitos estudos teóricos, discussões, seminários, gravações de vídeo aulas e organização de relatórios. O acompanhamento da disciplina se deu na universidade com a professora Adriana Oliveira de Sales e na comunidade com os professores: Adriana Oliveira de Sales, Andérbio Marcio Silva Martins, Hemerson Vargas Catão e Lívia Viégas. Ou seja, além do deslocamento dos 
alunos indígenas para a universidade, os professores também se deslocam para ministrarem aulas nas aldeias indígenas, possibilitando a alternância de espaços e saberes.

No tempo comunidade, os alunos desenvolveram atividades de estudos de materiais encaminhados e aplicação das atividades propostas. Momento impar na disciplina se deu quando eles, cheios de vivências das comunidades conseguiram apresentar e discutir na universidade, fazendo assim a reflexão mais crítica com relação ao ensino propriamente dito e todos os desafios que encontraram ao se colocar de fato na condição de professores responsáveis pela educação escolar.

A que se relatar que a questão da formação de professores indígenas tem se destacado nos últimos anos no cenário indígena e indigenista, quer enquanto reivindicação do movimento indígena - em especial dos professores - quer enquanto políticas públicas que procuram atender a essa demanda, que se insere no bojo da problemática da oficialização das escolas indígenas.

Dentre os inúmeros desafios para a formação de professores indígenas em nível superior, o tema central das aulas se deram reflexivamente sobre como os(as) alunos(as) universitários(as) indígenas já são professores(as) em suas aldeias, era preciso decidir que tipos de atividades caracterizariam este momento formativo e comporiam o estágio e como articular as ações de pesquisa e prática docente oportunizando a soma de esforços e produção de resultados que contribuíssem tanto para a formação do(a) professor(a) como para as escolas.

Essas práticas pedagógicas, uma vez explicitadas, narradas e pensadas por seus atores, ocupam importante e especial lugar na formação dos professores indígenas. Por meio desses registros, podem documentar para si e para os outros o seu "saber fazer" pedagógico e, ao mesmo tempo, planejar e avaliar, de forma mais intencional e consciente, as atividades cotidianas na escola e na comunidade.

Por meio do registro o professor em formação pôde: documentar os conhecimentos adquiridos, dúvidas, sínteses, relatos da prática pedagógica e questões para discussão coletiva; refletir sobre o processo pessoal de aprendizagem e sobre a prática pedagógica; recuperar o que foi aprendido e projetar novas aprendizagens; dialogar com as próprias representações, modificando-as gradativamente quando for o caso; refletir para buscar explicações e soluções para os problemas didáticos; documentar e socializar as experiências vividas; e criar meios para melhor organizar as suas rotinas de ensino.

Na disciplina oferecida de julho a dezembro de 2016, os alunos estudaram textos que apresentavam Paradigmas da Formação de Professores (Paquay, Léopold \& Wagner, Marie-Cécile. Competências Profissionais privilegiadas nos estágios e no vídeo formação In: Perrenoud, Philippe et all. Formando Professores Profissionais: Quais estratégias? Quais competências? Capítulo 8, 2001, p. 129). Estudaram ainda: Que Saberes o 
professor precisa construir no cenário Intercultural? (PICONEZ, STELA C. BERTHOLO. A prática de ensino e o estágio supervisionado. Campinas, SP: Papirus, 2006. 139p).

Posteriormente, assistiram vídeo aulas no you tube, seguido de explicações e elaborações de roteiros para gravações de vídeo aulas em Guarani/ Kaiowá e em Português como Segunda Língua. Trabalhamos essencialmente o uso do smartphone para registro das aulas planejadas. Preconizando que o uso dessa tecnologia está cada vez mais sendo utilizada pelas populações indígenas. Essas aulas gravadas de/em língua indígena foram alocadas numa página criada no you tube (Linguagens Teko Arandu https://www.youtube.com/channel/UCNSza2We8SOq4y1h9eAXRYQ) para que, além de uma atividade de sala de aula, haja visibilidade e os insira num espaço que não é ocupado por indígenas.

Dessa forma, houve o aprendizado de novas tecnologias e metodologias de ensino, além de utilizar essa ferramenta em favor da preservação das línguas indígenas. No tempo comunidade, cada aluno pode se organizar, planejar e desenvolver atividades de ensino em suas aldeias de diferentes formas. Muitos exemplos de atividades interdisciplinares podem ser constatados nos relatórios apresentados no final da disciplina em 2016.

No tocante a disciplina em 2017, os estudantes tiveram aulas teóricas envolvendo a formação de professores e puderam refletir sobre o Ensino Médio nas aldeias e as propostas de mudanças no Novo Ensino Médio. Assistiram um vídeo intitulado "Dois lados da Moeda: novo ensino médio" e puderam fazer um debate sobre essas alterações. Posteriormente, puderam vivenciar a elaboração de um curso preparatório para o vestibular da licenciatura indígena. Inicialmente estudaram o edital e como se organizava toda a seleção. Se apropriaram principalmente das provas de redações (língua indígena e língua portuguesa) e prova oral (língua indígena), com exemplos das provas anteriores. Segue relato de alguns dos alunos:

“ O primeiro dia de aula, iniciei o estágio para a turma, primeiramente me apresentei para eles, porque que estou me reunindo, comecei a falar sobre o Teko Arandu, perfil do acadêmico em geral do curso da universidade da UFGD e da FAIND, esclareci para eles a ideia que surgiram para fazer cursinho na aldeia, falei do meu curso da área de linguagens e de outras áreas que a FAIND tem, disse que somos cinco alunos do Panambizinho, já estão se formando em 2017, por isso tivemos a esperança de que os candidatos da aldeia Panambizinho passar no vestibular (.....) para conseguir a vaga, temos que estudar mesmo, fazer redação, ler texto em guarani e português, interpretar texto, ler de novo (...)"

(Concianza, Fábio. Relatório de estágio supervisionado. Aldeia Panambizinho. 23 de fevereiro de 2017.)

“Começamos o planejamento do curso em Janeiro, durante a etapa de T.U. Nos reunimos para fazer o plano de aula, pesquisando sobre os conteúdo a serem ministrados durante as aulas. Os conteúdos são sobre redação dissertativo - 
argumentativo e gênero narrativo, como fazer uma boa redação em Língua Portuguesa e língua guarani, a estrutura textual (...).Na aldeia, procuramos os candidatos que se interessassem a fazer o vestibular e divulgamos em cartaz na escola o horário e dia do início do cursinho. Fizemos inscrições na escola e nas casas dos candidatos, em média de 40 inscrições foram feitas na aldeia Sassoró e duas áreas de retomada Pyelito Kue(...).

(Cleonice Duarte, Dila Castelão Duarte, Waneide G. Duarte. Relatório de Estágio Supervisionado. Aldeia Sassoró.16 de fevereiro de 2017.)

Por fim, as atividades aliadas a disciplina de estágio promoveram antes de qualquer coisa, o reconhecimento da realidade escolar e sociolinguística desses estudantes, também sobre ensino, tanto a língua guarani como a língua portuguesa, observamos que existe uma lacuna na reflexão sobre o processo de ensino dessas línguas.

\section{CONSIDERAÇÕES FINAIS}

Identificamos que atualmente a língua portuguesa está bastante presente no cotidiano das famílias nas áreas indígenas, seja por meio do rádio ou da televisão, mas sobretudo pelas novas tecnologias de comunicação. Da mesma forma, observamos que a língua guarani, na sua modalidade escrita, também começa a se fazer presente no uso de redes sociais. $E$ que a modalidade oral se faz presente em todos os ambientes da comunidade. Conseguiram aliar tecnologias, o uso de smartphone, como um instrumento possível de preservação da língua indígena, e ainda, fortalecer por meio do trabalho com gêneros escritos e orais, o vestibular diferenciado - PSLIN - para a entrada no curso de Licenciatura Indígena.

O curso possibilita a mim como docente e a Universidade Federal da Grande Dourados, momentos de aprendizado. Trabalhar com uma sociedade diferenciada é um verdadeiro processo de desconstrução, principalmente do como percebemos os processos de ensino. Poder desenvolver atividades que promovam tanta dinamicidade pode parecer inovador para nós, mas para essas populações, tudo está relacionado. Tudo tem continuidade. As atividades desenvolvidas no Estágio, estão relacionados ao aprendizado como professores, que estão relacionadas a melhorias nas comunidades e que estão relacionados ao cotidiano da escola e do viver bem. Devemos aprender mais com os povos indígenas.

\section{REFERÊNCIAS}

AMADO, R.S. O ensino e a pesquisa de português para falantes de outras línguas. Guavira Letras, Três Lagoas, v. 6, p. 67-75, 2008. 
BRASIL, Lei de Diretrizes e Bases da Educação - Lei Federal n. ${ }^{\circ}$ 9.394/96. In: Diário oficial da República Federativa do Brasil, n. ${ }^{\circ}$ 248, de 23 de dezembro de 1996.. Brasília DF, 1996;

, Diretrizes para a Política Nacional de Educação Escolar - elaborado pelo Comitê Escolar Indígena. Brasília: MEC/SEF/DPEF, 1993. p.24.

,Constituição da República Federativa do Brasil - 1988 Brasília: Senado Federal, Subsecretaria de edições Técnicas, 1999;

Ministério da Educação. Referencial Curricular Nacional para as Escolas Indígenas. Brasília: MEC, 1998.

Cardoso, Valéria Faria. Aspectos morfossintáticos da língua Kaiowá (Guarani. Campinas, SP. 2008.

D’ANGELIS, Wilmar da Rocha. Aprisionando sonhos: a educação escolar indígena no Brasil. 1a. ed. Campinas, SP: Editora Curt Nimuendajú, 2012. 256p .

MAHER, T. M. MAHER, T. M. Em Busca de Conforto Linguístico e Metodológico no Acre Indígena. Trabalhos em Linguística Aplicada, 47, ago./dez.2008, p. 409-428.

MARTINS, Andérbio Márcio Silva; CHAMORRO, Graciela. Diversidade linguística em Mato Grosso do Sul. CHAMORRO, Graciela \& COMBÈS, Isabelle (Org.) Povos indígenas em Mato Grosso do Sul: história, cultura e transformações sociais. Ed.

UFGD, Dourados, 2015

MARTINS, A. M; KNAPP, C. Oralidade e escrita em escolas indígenas guarani e kaiowá. Desafios e possibilidades de um ensino bilíngue. Voces y Silencios: Revista Latinoamericana de Educación, Vol. 7, No. 2, 53-73 ISSN: 2215-8421.

MARCUSCHI, Luiz Antônio. A concepção de língua falada nos manuais de português de $1^{\circ}$ e $2^{\circ}$ graus: uma visão crítica. Trabalhos em Linguística Aplicada. Campinas: UNICAMP/IEL, no 30, 1997.

MELIÀ, Bartomeu (1992). La lengua Guaraní del Paraguay. Madrid: Editorial Mapfre.

MOITA LOPES, L. P. Uma Lingüística Aplicada Mestiça e Ideológica: Interrogando o campo como linguista aplicado. In: MOITA LOPES, L. P. (org.) Por uma Linguística Aplicada Indisciplinar. São Paulo: Parábola Editorial, 2006.

UFGD. FAIND. Curso de Licenciatura Intercultural Indígena - Teko Arandu. Projeto Pedagógico, Dourados: [s.n], 2012. 
*Discente da Faculdade Intercultural indígena -FAIND-UFGD 